\title{
CHARACTERISTICS OF FEDERAL CORRECTIONAL INSTITUTIONS AND \\ INMATE ADJUSTMENT TO INCARCERATION
}

by

Michael S. Martin

B.A., Carleton University, 2007

\begin{abstract}
A thesis submitted to
the Faculty of Graduate and Postdoctoral Affairs

in partial fulfillment of the requirements for the degree of
\end{abstract}

Master of Arts

in

Psychology

Carleton University

Ottawa, Canada

(C2011, Michael S. Martin 
Library and Archives

Canada

Published Heritage

Branch

395 Wellington Street

Ottawa ON K1A ON4

Canada
Bibliothèque et

Archives Canada

Direction du

Patrimoine de l'édition

395 , rue Wellington

Ottawa ON K1A ON4

Canada
Your file Votre référence

ISBN: 978-0-494-83083-3

Our file Notre référence

ISBN: 978-0-494-83083-3
NOTICE:

The author has granted a nonexclusive license allowing Library and Archives Canada to reproduce, publish, archive, preserve, conserve, communicate to the public by telecommunication or on the Internet, loan, distribute and sell theses worldwide, for commercial or noncommercial purposes, in microform, paper, electronic and/or any other formats.

The author retains copyright ownership and moral rights in this thesis. Neither the thesis nor substantial extracts from it may be printed or otherwise reproduced without the author's permission.
AVIS:

L'auteur a accordé une licence non exclusive permettant à la Bibliothèque et Archives Canada de reproduire, publier, archiver, sauvegarder, conserver, transmettre au public par télécommunication ou par l'Internet, prêter, distribuer et vendre des thèses partout dans le monde, à des fins commerciales ou autres, sur support microforme, papier, électronique et/ou autres formats.

L'auteur conserve la propriété du droit d'auteur et des droits moraux qui protège cette thèse. $\mathrm{Ni}$ la thèse ni des extraits substantiels de celle-ci ne doivent être imprimés ou autrement reproduits sans son autorisation.
In compliance with the Canadian Privacy Act some supporting forms may have been removed from this thesis.

While these forms may be included in the document page count, their removal does not represent any loss of content from the thesis.
Conformément à la loi canadienne sur la protection de la vie privée, quelques formulaires secondaires ont été enlevés de cette thèse.

Bien que ces formulaires aient inclus dans la pagination, il n'y aura aucun contenu manquant. 


\begin{abstract}
Past research on institutional characteristics that are related to inmate misconduct have found mixed results. The current review sought to integrate various theoretical frameworks from the correctional and social capital literatures to reconcile some of these past findings. Data from 52 federal correctional institutions over a six year period were analyzed using pooled time series analysis (PTSA) to assess the relationships between environmental factors and institutional misconduct, after controlling for well known risk related variables. As the majority of variability in misconduct was accounted for by individual site differences, conclusions about specific predictors are highly tentative. Nonetheless, the results do suggest that altering the environmental factors of correctional institutions could result in reductions in rule violations and behavioural incidents among inmates.
\end{abstract}




\section{Acknowledgements}

This research was supported by Correctional Service of Canada (CSC) through access to many of its databases and considerable feedback and support from a range of staff within the organization. However, the views and findings herein are those solely of the author, and do not reflect the official position of CSC. The author would like to acknowledge the numerous staff from CSC's Research and Mental Health Branches who provided feedback following their attendance at presentations of the proposed study and/or after reviewing written proposals and draft documents. Thanks in particular to Ashley Wamboldt for the countless hours of assistance in extracting, aggregating and understanding the hundreds of thousands of lines of data behind this project. While too many to list individually, the support of the countless other CSC employees and the experiences they were able to share with me were invaluable in the development of the research question and execution of the study.

I also express my sincere appreciation to my supervisor, Dr. Frank Elgar for his valuable guidance, support, feedback and encouragement throughout the process. Thanks also to my committee members, Drs. Shelley Brown and Kelley Blanchette for sharing their expertise and knowledge in refining the study questions and design. The range of perspectives, experiences and knowledge brought to the table by my entire committee has provided me with new avenues to explore in my continued educational and employment endeavours.

Finally, thanks to the long list of family and friends who supported me through this project at every turn, and to my four-legged friend Friar for ensuring regular breaks and fresh air when they were most needed. 


\section{Table of Contents}

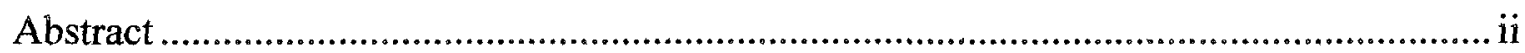

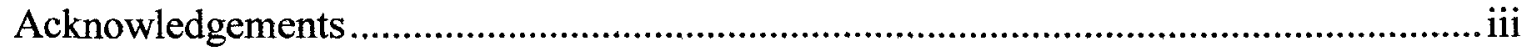



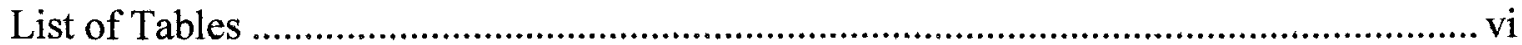

Characteristics of Federal Correctional Institutions and Inmate Adjustment to

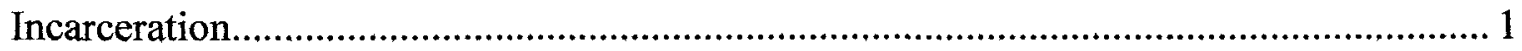

Theories of Inmate Adjustment to Incarceration ...................................................... 1

Inmate Mental Health and Institutional Adjustment.................................................. 5

Factors of Incarceration Which May Influence Inmate Adjustment.............................. 9

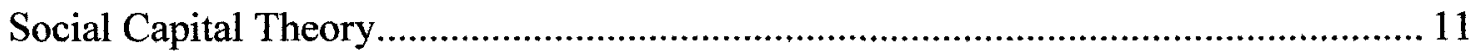

Social Capital Outcome Research ............................................................................. 14

Integrating Correctional and Social Capital Research .................................................. 15

Current Study Research Questions and Hypotheses .................................................... 16

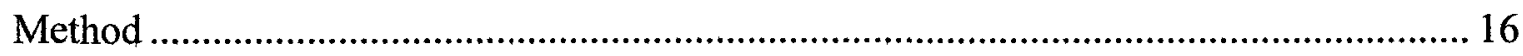

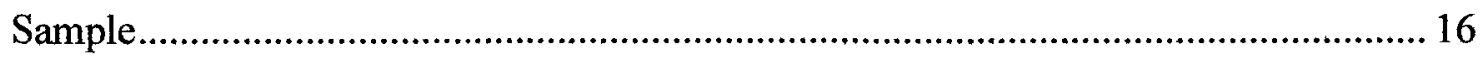

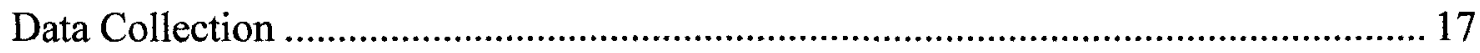

CSC/NPB Data Warehouse

Psychology and Mental Health Tracking Database ................................................. 17

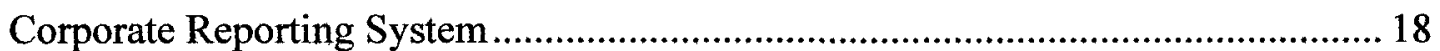

Computerized Mental Health Intake Screening System .......................................... 19

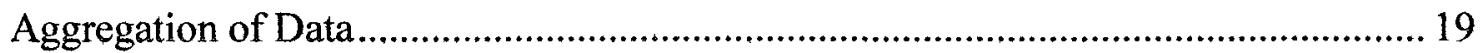

Measures $\ldots \ldots \ldots \ldots \ldots \ldots \ldots \ldots \ldots \ldots \ldots \ldots \ldots \ldots \ldots \ldots \ldots \ldots \ldots \ldots \ldots \ldots \ldots \ldots \ldots \ldots \ldots \ldots \ldots \ldots \ldots \ldots \ldots \ldots \ldots \ldots \ldots \ldots \ldots \ldots \ldots \ldots \ldots \ldots \ldots \ldots \ldots \ldots \ldots \ldots \ldots \ldots \ldots \ldots \ldots \ldots \ldots \ldots \ldots \ldots \ldots \ldots$ 
Analyses 20

Results 24

Collinearity and Other Statistical Assumptions 24

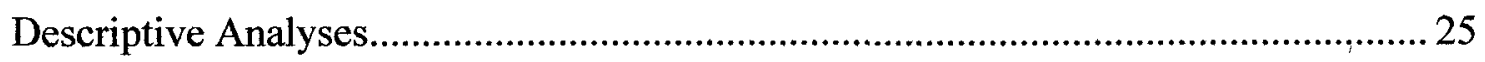

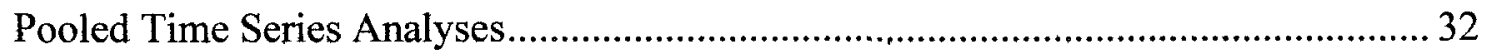

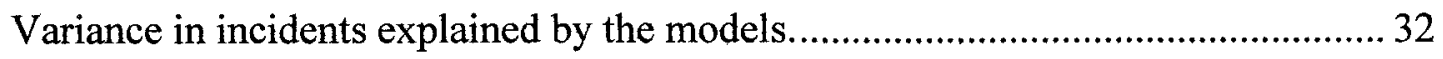

Significant predictors of incidents. .......................................................... 34

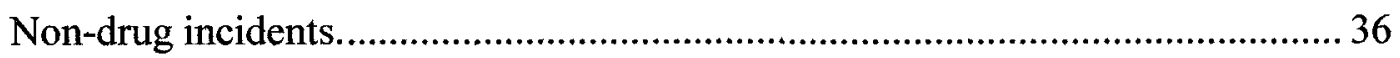

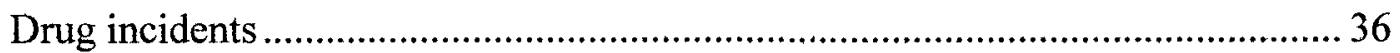

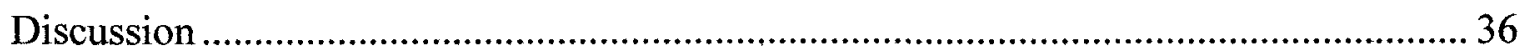

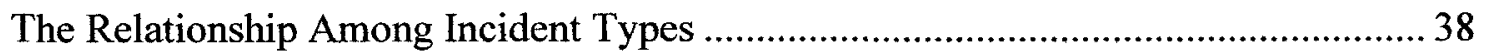

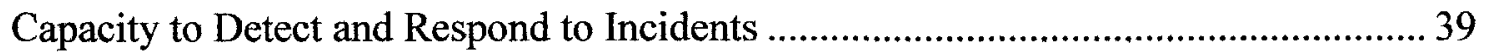

Capacity to Respond to Cultural Differences ....................................................... 40

Capacity to Address Criminogenic Risk Factors ................................................ 41



Population Stability and Institutional Incidents ................................................ 43

Staff Capacity to Respond to Mental Health Issues.......................................... 44

Limitations and Future Directions ............................................................. 44

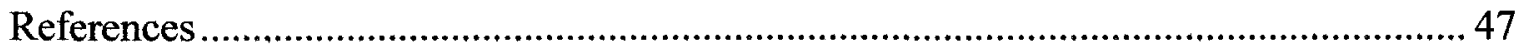




\section{List of Tables}

Table 1. Comparison of theories of institutional adjustment....................................... 5

Table 2. Relationship between prison environmental factors and social capital



Table 3. Institutional characteristics: measures and data sources. ........................... 21

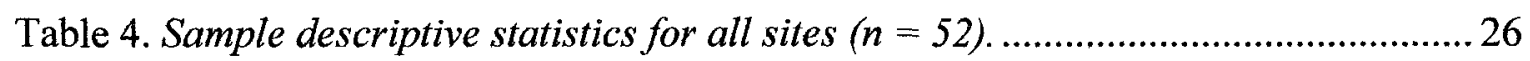

Table 5. Sample descriptive statistics by security level. .......................................... 28

Table 6. PTSA results of incidents regressed on predictor variables ........................... 33 
Characteristics of Federal Correctional Institutions and Inmate Adjustment to Incarceration

The prison environment is stressful (Toch, 1992/1977) and influences inmates' lives through its physical structure and the daily activities and routines that characterize prison life (Bottoms, 1999). As noted by Haney (2002), "the psychological effects of incarceration vary from individual to individual and are often reversible. [...] But few people are completely unchanged or unscathed by the experience" (p. 4). Furthermore, Haney (2002) argues "most people agree that the more extreme, harsh, dangerous, or otherwise psychologically taxing the nature of the confinement, the greater the number of people who will suffer and the deeper the damage that they will incur" (p. 5).

In recent years, the Correctional Service of Canada (CSC) has among its priorities reinforced the importance of maintaining the safety and security of staff and inmates, enhancing capacity to respond to the mental health needs of inmates and enhancing capacity to provide effective interventions for Aboriginal offenders (CSC, 2008, 2009a, $2010,2011)$. Given these priorities, the current study sought to measure recent changes on various institutional characteristics in order to identify environmental predictors of inmate adjustment (i.e. rates of incidents and rule infractions).

\section{Theories of Inmate Adjustment to Incarceration}

One of the best known (and most debated) theories of institutional adjustment is the deprivation model. This theory posits that environmental factors such as overcrowding, isolation, and lack of privacy (collectively referred to as the pains of incarceration) that inmates face upon arrival in prison shape their behaviour. Some researchers suggest that inmates adapt to these stressful and oppressive conditions 
through the process of prisonization. It has been argued as part of this process, inmates assume new attitudes and behaviours reflective of the prison culture and the inmate code (e.g. Clemmer, 1958/1940; Piepgras, 2006; Sykes, 1958). The adoption of the prison culture and the inmate code is suggested by Clemmer (1958/1940) to pose challenges for the individual upon release to the community, as many of the behaviours which are adaptive in prison are maladaptive in the society at large.

As outlined by Piepgras (2006) the rules that make up the inmate code appear to have shifted somewhat over time. Originally, researchers such as Sykes, perceived the value of the inmate code as one that promoted cohesiveness among inmates. The key function of this code was to alleviate stressors and the pains of incarceration. More recently, the emphasis of the inmate code appears oriented towards promoting individual safety. Cooley (1992) argues that the inmate code serves a dual function. On the one hand the inmate code creates social cohesion by defining appropriate behaviours among inmates. By contrast, the inmate code may divide inmates through rules such as "do your own time" and "trust nobody", which discourage relationships and cohesion. Inmates who violate the code - a frequent occurrence according to Cooley (1992) - also risk alienation and victimization.

Regardless of the exact rules that make up the inmate code, it has been argued that this deprivation model overlooks the role of management. As noted by Dilulio (1987) "if Sykes and most other experts were to be believed, any attempt by prison personnel to run a tighter, cleaner ship would only result in more problems" (p.3). Thus, a governance model was proposed in response to this perceived limitation. This model suggests that social and political factors such as management styles, staff training, staff-inmate 
interactions, and policies at the very least moderate the impact of incarceration on inmates. Nonetheless, such a model concedes that factors beyond the control of inmates and tied to the correctional system as a whole - may have consequences for their health and/or behaviour.

At the opposite end of the spectrum, the importation theory explains prison adjustment as a function of the particular set of values and roles that inmates bring into the system. It suggests that inmate behaviour throughout incarceration is highly similar to that which they demonstrated pre-incarceration (Irwin \& Cressey, 1962). These values and roles are thought of as a function of factors such as age, sex, class, ethnicity, prior criminality, and employment and education history, among others. Proponents of the importation theory suggest that "behaviour patterns among inmates develop with a minimum of impact from the outside world" (Irwin \& Cressey, 1962, p.142-143). It should be noted that deprivation theorists also acknowledge the role of these individual characteristics, albeit to a lesser extent. For example, Clemmer (1958/1940) acknowledges that the degree of prisonization varies based on a range of factors, with the first one being the individual's personality as a reflection of the relationships and experiences he or she had prior to incarceration. These individual factors such as age, sex, criminal history, and antisocial peers and attitudes, are among the best known predictors of crime and institutional misconduct (Andrews \& Bonta, 2010; Gendreau, Goggin, \& Law, 1997).

However, the importation theory cannot account for the fact that prison misconducts such as assaults, theft and disobeying orders can be reduced through correctional programming (French \& Gendreau, 2006, Zamble \& Porporino, 1988, 1990). 
It may be that individual characteristics moderate the relationship between the institutional environment and prison misconduct. This moderating effect of individual differences is more explicitly reflected in a fourth theory, which focuses on how inmates cope with and adapt to institutional stressors. In many ways the model reflects a hybrid approach to looking at individual and environmental factors. Specifically, it acknowledges that inmates face stressors within the prison environment, but it considers individual differences such as coping strategies to explain inmate adjustment to incarceration (Bonta \& Gendreau, 1990; Toch, 1992/1977; Zamble \& Porporino, 1988, 1990). However, Zamble and Porporino (1990) acknowledge that the level of coping difficulties among inmates was "much more severe and widespread than our expectations" (p. 56), suggesting that many inmates likely are unable to cope with the stressors that incarceration presents.

Table 1 summarizes the deprivation, governance, importation and coping/adaptation theories of institutional adjustment. Previous empirical findings in support of each theory, to be discussed in the next sections, point towards the need to integrate these theories and consider the interaction between individual and environmental predictors of institutional adjustment. The importation theory is useful to identify historical factors that correctional staff must be mindful of in terms of an inmate's potential to positively adjust to incarceration. On the other hand, the deprivation and coping/adaptation theories identify individual and environmental factors that can be targeted to improve adjustment to incarceration. 
Table 1.

Comparison of theories of institutional adjustment.

\begin{tabular}{|c|c|c|c|c|}
\hline & Deprivation & Governance & Importation & $\begin{array}{l}\text { Coping/ } \\
\text { Adaptation }\end{array}$ \\
\hline Level of & Environment/ & Management & Individual & Interaction \\
\hline analysis & Context & practices & & $\begin{array}{l}\text { between } \\
\text { individual and } \\
\text { environment }\end{array}$ \\
\hline & Environment can & Environment and & Mostly static and & Programs and \\
\hline factors & be modified & $\begin{array}{l}\text { behaviour can be } \\
\text { altered through } \\
\text { management } \\
\text { decisions }\end{array}$ & unchangeable. & $\begin{array}{l}\text { other } \\
\text { interventions can } \\
\text { target need areas }\end{array}$ \\
\hline Examples & Crowding, lack & Policies and & Age, race, & Coping skills, \\
\hline of factors & $\begin{array}{l}\text { of activity, lack } \\
\text { of privacy }\end{array}$ & $\begin{array}{l}\text { rules, staffing, } \\
\text { training }\end{array}$ & criminal history & problem solving \\
\hline
\end{tabular}

\section{Inmate Mental Health and Institutional Adjustment}

Ensuring that comprehensive mental health services are in place is "urgently required" given that mental health issues are common in the correctional setting (e.g., Brink, Doherty, Boer, 2001; Fazel \& Danesh, 2002; Motiuk \& Porporino, 1991), and that the rate of mental health issues has increased in recent years (Correctional Service of Canada, 2009a, 2009b; Office of the Correctional Investigator [OCI], 2008, p.35). While 
the complex link between mental disorder and violence and/or criminality is debated ${ }^{1}$, individuals with mental health issues typically display coping difficuities (Haney, 2002; Toch \& Adams, 1986). In line with the coping/adaptation theory discussed previously, these difficulties may result in higher rates of institutional misconduct. For example, Baskin, Sommers and Steadman (1991) found that those with depressed symptoms were more likely to engage in self-directed violence, while those with "confusion" symptoms were more likely to direct violence towards staff and other inmates ${ }^{2}$. Toch and Kupers (2007) in reviewing recent research confirmed this relationship between individuals with mental health issues and institutional misconduct and violence. Furthermore, research on inmates in segregation indicates that mental health issues are more common among segregated as opposed to non-segregated inmates (Motiuk \& Blanchette, 1997; Zinger \& Wichman, 1999). Toch and Adams (1986) note that rates of institutional misconduct are higher among those with mental health issues, but that these rates may vary among diagnostic categories. For example, individuals with antisocial personality disorder, disorganized schizophrenia, and adjustment disorders with conduct disturbance incurred a greater number of infractions.

\footnotetext{
${ }^{1}$ Some research suggests an increased risk of violence among individuals with severe mental illness (e.g. Arsenault, Moffitt, Capsi, Taylor, \& Silva, 2000; Hodgins and Janson, 2002). Other researchers, however, suggest the relationship is explained by the fact that individuals with mental disorder are more likely to present with risk factors for violence, in particular substance use and psychopathy (e.g. Angermeyer, Cooper, \& Link, 1998; Hiday, 2006; Monahan et al., 2001; Steadman et al, 1998), but that it is these risk factors that cause violence and not mental disorder in and of itself. A third group of researchers suggest that only specific active symptoms are linked to violence (e.g. Link, Andrews, \& Cullen, 1992; Link, Stueve, \& Phellan, 1998).

${ }^{2}$ The 'confusion' scale included the following five items: "has trouble remembering, has difficulty completing even simple task on his own, gets confused, has to be reminded of what to do, and has to be told to follow the facility routine" (Baskin et al., 1991, p.279).
} 
It has also been suggested that unrecognized and untreated mental health issues and the need to respond to chailenging behaviours (whether due to mental health or otherwise) may have implications for the mental health of prison staff (World Health Organization, 2006). A focus group with 31 inmates and 21 prison staff from two institutions in England (one medium security male institution, and a rehabilitation unit for female offenders) identified five factors in the prison environment that influenced inmate mental health: isolation and lack of activity, prevalence of drug misuse, lack of family contact, a cycle of negative attitudes between inmates and staff, and bullying (Nurse, Woodcock, \& Ormsby, 2003). Additionally, poor management and communication, lack of information, poor continuity of care, reduced staffing levels, prison culture (e.g. the expectation that staff are supposed to be tough), and fear for safety were identified as factors which cause stress and potential mental health concerns for staff. It was further suggested, that these causes of stress for staff interact with one another and create circles of stress, (Nurse et al., 2003, p. 482-483). These circles of stress in turn lead to further impacts on inmates, such as higher rates of staff illness resulting in increased lock-up times for inmates, increased tension and negative staff-inmate relationships.

In line with these theorized circles of stress, some studies suggest that correctional officers hold negative attitudes towards inmates either in general (Lavoie, Connolly, \& Roesch, 2006) or specifically towards those with major mental and personality disorders (Bowers, Carr-Walker, Allan, Callaghan, Nijman \& Paton, 2006; Callahan, 2004). It is noted that this is particularly the case where staff burnout or lack of training are prevalent (Lavoie et al., 2006). Given that correctional officers are the primary contact with inmates, and provide a great deal of informal mental health services (Applebaum, 
Hickey, \& Packer, 2001; Dvoskin \& Spiers, 2004), such attitudes may perpetuate existing stigma towards mental health or other issues contributing to the offenders criminality (Edwards, 2000). This may in turn reduce the likelihood of inmates fully participating in treatment and programming.

Furthermore, the findings of recent research on ex-offender involvement in psychiatric treatment following release suggest another potential implication of staff attitudes within prisons. Recent research (Piepgras, 2006; Rotter, McQuistion, Broner, \& Steinbacher, 2005) indicates that psychiatric inpatients with correctional histories are more likely to demonstrate symptoms and behaviours reflective of prisonization, such as suspiciousness of others, perceived importance of respect, intimidating and manipulative behaviours, refusing to disclose information and "an overall attitude of just getting through as opposed to therapeutically improving" (Carr et al., 2006, p. 573). It is possible that some of these behaviours may be more prevalent among former inmates who perceived negative attitudes among correctional staff, although this does not appear to have been explored in past research.

The findings of a study conducted in Ontario (Motiuk \& Porporino, 1994), further highlight the impact of staff attitudes towards inmates with mental disorders. In this study, 36 federal offenders in Ontario who met the Diagnostic Interview Schedule criteria for a lifetime diagnosis of manic episode, schizophrenia or schizophreniform disorder were matched with 36 offenders who were similar on various other factors (e.g. age, type of offence, length of sentence) but did not meet the criteria for one of these disorders. While incident rates were similar between groups, the group with mental disorders in this study were less likely to receive parole and more likely to be suspended when released 
than those without a mental disorder. The authors suggest that correctional and parole board staff may be more cautious in their decision making when working with offenders with mental disorder. It has been suggested that this exercise of caution may be due to the perception that offenders with mental health issues are more dangerous. Alternatively, staff may lack confidence to effectively manage this population due to a lack of training and support (Motiuk \& Porporino, 1994).

As seen in various contexts, the concepts of therapeutic relationships or therapeutic alliance emphasize the importance of the relationship between treatment team members and service users. Past research suggests that this relationship predicts more favourable outcomes such as engaging in service, adhering to treatment, and reduction of symptoms (Priebe \& McCabe, 2008). In fact, Priebe et al. (2007) suggest that therapeutic alliance may be a form of therapy in and of itself that can lead to more positive outcomes. While other explanations need to be ruled out, addressing negative attitudes towards inmates with mental health issues through training and education may result in improved institutional adjustment among inmates with mental disorders (Gunn, 2000).

\section{Factors of Incarceration Which May Influence Inmate Adjustment}

While the research presented above has largely focused on individuals with mental health needs, others have observed similar responses to incarceration among inmates without mental health needs. For example, Clements (1979) argues that inmates may respond to overcrowding issues by withdrawing, becoming increasingly vigilant and suspicious, and/or engaging in acts of verbal or physical aggression to adjust to the challenges they face. While these behaviours would generally be seen as maladaptive, in the prison environment these may serve as coping mechanisms leading to benefits such as 
relief from overcrowding through a transfer to another cell or institution. Furthermore, despite the previously discussed coping differences among inmates, "given the inability to perform other coping strategies" the likelihood of employing a response such as violence to respond to given stressors may increase (Clements, 1979, p. 223).

A substantial body of past research has considered the relationship between crowding and institutional misconduct, with mixed results coming from these studies. Some of these studies (e.g., Cox, Paulhus, \& McCain, 1984, 1986; Gaes \& McGuire, 1985) reported a positive relationship between crowding and misconduct, whereas others found a negative relationship (e.g., Porporino, 1986). Results of a meta-analysis combining data from sixteen studies indicate that overcrowding has a limited overall effect on inmate misconduct, with a mean weighted effect size of $r=0.025$. However, an interaction between age and overcrowding was observed when calculating estimates separately by age group. Specifically, studies with younger inmates (eighteen to twentyfive years old) had a mean weighted effect size of $r=0.34$ (Franklin, Franklin, \& Pratt, 2006). There was no relationship between crowding and incident rates for any of the other age categories considered. The authors of the review note that younger offenders show greater adjustment difficulties to inmate life (Goodstein \& Wright, 1989; McShane \& Williams, 1989, both cited in Franklin et al., 2006). They appear to imply that these adjustment difficulties are magnified in crowded institutions. However, to date the current author is unaware of this theory having been tested further.

Franklin et al. (2006) posited that the overall results of their meta-analysis provide greater support for the relationship between management practices and inmate misconduct. Previous research suggests that management and situational factors, such as 
staff turnover and training, effective use of programs to keep inmates from idling, and staff-inmate ratios all are negatively related to inmate misconduct (dilulio, 1987; Gaes \& McGuire, 1985; McCorkle, Miethe, \& Drass, 1995; Porporino, 1986). McCorkle et al. (1995) also included factors such as the ratio of white-black staff and guard-inmate ratios within prison management variables in their study, and observed an increase in staff and inmate assaults corresponding to increases in the white-black ratios. These findings may suggest the need to consider the ethnic diversity of institutional staff (particularly relative to the ethnic makeup of the inmate population). Such considerations are likely to be of even greater importance if there are any underlying ethnic or racial tensions among inmates or between inmates and staff

\section{Social Capital Theory}

Beyond the previous literature on inmate adjustment from researchers in the correctional field, another growing theoretical framework - social capital theory - was considered to further the understanding of the impacts of incarceration on inmate behaviour. There were many areas in which social capital theory overlapped with the existing correctional literature. In other areas, it offered either new factors for consideration or alternative explanations for conflicting findings within the correctional literature.

While there are various definitions of social capital (e.g., Coleman, 1988; Portes, 2000; Putnam, 2000), key themes and components emerge from the various existing literature in the area. At its simplest level, social capital can be understood as the "degree of connectedness and the quality and quantity of social relations within a given population" (Harpham, Grant \& Thomas, 2002, p. 106). Four overlapping constructs of 
social capital have been identified: collective efficacy (i.e. the ability to respond to specific situational demands), psychological sense of community (i.e. shared values and perceived benefit of participation in the group), neighbourhood cohesion (i.e. social interaction and support) and community competence (i.e. collective problem solving skills; Lochner, Kawachi \& Kennedy, 1999).

Furthermore, the distinction has been made between the structural and cognitive components of social capital (Colletta \& Cullen, 2000; Uphoff, 2000). Structural components refer primarily to more tangible components such as networks, rules, and institutions, whereas the cognitive components are primarily those things that people feel, such as perceptions of support, reciprocity, sharing and trust (Harpham et al., 2002; McKenzie, Whitley \& Weich, 2002). One final distinction that has been advanced in the literature is that between bonding, bridging, and linking capital (Harpham et al., 2002; Putnam, 2000). Bonding capital reflects the interconnectedness between individuals who share common characteristics and interests. By comparison bridging capital refers to those relationships between groups who differ in one or more key ways, but for whom cooperation may provide benefits (or avoid potential harm) to both groups. Finally, linking social capital considers relationships between communities and formal institutions such as government, courts, the police, etc. (de Silva, McKenzie, Harpham \& Huttly, 2005).

The bonding and bridging capital distinction is one that appears to be particularly important within the prison environment. For example, the adoption of the inmate code may reflect bonding among inmates. Conversely, tensions between inmates and staff may reflect insufficient bridging capital between the two groups. The structural and cognitive 
components of social capital also appear to fit well with the existing theoretical perspectives on inmate adjustment. Cognitive aspects such as fear for safety, and trust between staff and inmates are suggested by Nurse et al. (2003) as being important to inmate mental health. Structural components of social capital are reflected within the deprivation and management models of adaptation to incarceration, including levels of activity, and contact with outside individuals (e.g. family and friends). Furthermore, events within the prison such as drug use or bullying may reflect either a lack of community competence to respond to these behaviours, and may either build a sense of community (i.e. a shared value of the use of drugs as a coping strategy) or work against establishing a sense of community (i.e. those who are victimized may be excluded from the larger inmate culture). Table 2 further explores the possible fit between incarceration and the core components of social capital.

Table 2.

Relationship between prison environmental factors and social capital components.

\begin{tabular}{lll}
\hline Factor & Social capital component & Type of social capital \\
\hline Activity/Preventing Idling & Neighbourhood cohesion & Structural/Bonding \\
Visits with family and others & Neighbourhood cohesion & Structural/Bridging \\
Staffing levels & Community competence / & Structural/Bonding \\
& collective efficacy & and Bridging \\
Timely provision of services & Community competence / & Structural/Bridging \\
and programs & collective efficacy & and Linking \\
Staff training & Community competence & Structural/Bridging \\
\hline
\end{tabular}




\section{Social Capital Outcome Research}

Significant correlations have been reported between social capital indices and self-rated health (Kawachi, Kennedy \& Glass, 1999), mortality (Kawachi, Kennedy, Lochner, \& Prothrow-Stith, 1997), and health related quality of life (Caperchione, Lauder, Kolt, Duncan, \& Mummery, 2008). Most relevant to the current research both in terms of design and its findings is a previous study looking at individual and community level characteristics and violence (Sampson, Raudenbush, \& Earls, 1997). The authors created a collective efficacy measure based on whether individuals self-reported that they would intervene in a range of situations (e.g. vandalism, fights, etc.) and if they perceived their neighbours as willing to help one another. Residential stability was also assessed, under the assumption that high mobility "especially in areas of decreasing population, fosters institutional disruption and weakened social controls over collective life." (Sampson et al., p. 919). This measure consisted of two items assessing whether the resident was in the same house ten years earlier, and if the house was occupied by the owner or a tenant. After controlling for aggregated individual differences, there were negative relationships between collective efficacy and perceived violence, actual violent victimization and murder rates. Relationships were mixed for neighbourhood stability. It was negatively related to perceived violence, unrelated to actual violent victimization and positively related to homicide rates. These findings that capacity to respond to various situations and population stability are related to violence in a community setting warrant further exploration in an institutional setting.

This study also highlights some of the methodological debate in assessing the relationship between community level factors and outcomes. One of these key issues is 
whether social capital is an individual or group level characteristic (de Silva et al, 2005). It is suggested that as opposed to social networks and support, "social capital is a feature of the social structure, not of the individual actors within the social structure; it is an ecologic characteristic" (Lochner et al., 1999, p. 260). Measured at the ecologic level, social capital can be an aggregation of individual responses to the group/community level as in the Sampson et al. (1997) study (see also, Kawachi et al., 1999). However, others have measured social capital directly through "ecologic observations" or "integral variables" (e.g., whether gas stations require pre-payment as an indicator of trust; Harpham et al., 2002; Lochner et al., 1999).

\section{Integrating Correctional and Social Capital Research}

As discussed above, a wide range of individual and environmental factors have been identified as potential predictors of inmate misconduct. Given that much of the past research has considered these factors in isolation of one another, there have been numerous mixed relationships reported in the literature. Furthermore, when considering environmental factors, researchers have often committed ecological fallacies, by failing to account for individual differences on key risk factors when generalizing the results of aggregated data to make individual predictions (Andrews \& Bonta, 2010). These various studies have employed diverse methodologies, each with their own strengths and weaknesses, which has further contributed to mixed relationships amongst the variables of interest. By drawing upon this past literature and seeking to integrate the various theoretical perspectives, it may be possible to clarify the relationships between institutional characteristics and rates of inmate adjustment. 


\section{Current Study Research Questions and Hypotheses}

The aim of the current study was to explore environmental and ecological predictors of adjustment among inmates in Canadian federal penitentiaries (i.e. those serving sentences of two years or longer), while controlling for well-known individual

predictors of such outcomes (c.f. Sampson et al., 1997). Specifically, the study examined links between environmental factors and incident rates in CSC institutions. It was hypothesized that these factors (as defined in Table 3 in the Methods section below) would predict adjustment to incarceration among federally sentenced inmates in the directions specified in Table 3. To test this hypothesis, a longitudinal ecological survey of federal correctional institutions in Canada was conducted. Quarterly data from the Correctional Service of Canada's corporate reporting and management systems from January 2005 through December 2010 were analyzed, using sites as the unit of analysis. The longitudinal design (using data from a six year period) was intended to address shortcomings of previous cross-sectional research.

\section{Method}

\section{Sample}

On any given day during the 2009-10 fiscal year, an average of 13,500 offenders were incarcerated within CSC institutions. This number has been increasing over recent years and is expected to continue to increase with new crime legislation. (CSC, 2011; see also Public Safety Canada, 2009; Sampson, Gascon, Glen, Louie, \& Rosenfeldt, 2007). However, as data were aggregated in the current study to the institutional level, the 
sampling units were 52 federal Canadian correctional institutions ${ }^{3}$ - including women's institutions and treatment centres - managed by CSC. Through the use of pooled time series analysis the total sample of quarterly observations was 1,248 (52 institutions x 6 years $\times 4$ quarters/year $=1,248$ ), as each repeated observation is treated as an individual case under this approach, which is discussed in greater detail below.

\section{Data Collection}

The current study was conducted using archival/secondary records from four data sources maintained by Correctional Service of Canada: (1) CSC/NPB Data Warehouse; (2) the Psychology and Mental Health Tracking Database (PMHTD); (3) Corporate Reporting System (CRS); and (4) the Computerized Mental Health Intake Screening System (CoMHISS).

CSC/NPB Data Warehouse. The Offender Management System (OMS) is the official case management system used by Correctional Service of Canada. Each offender is entered into the system, and the majority of reports on that particular offender are filed on the system. Data from OMS is archived in the CSC/NPB Data Warehouse for reporting purposes, which was extracted using SQL statements in Microsoft Query. Data used for this project were current as of April 2, 2011.

Psychology and Mental Health Tracking Database (PMHTD). This database was fully implemented nationally as of April 1,2010 after a pilot period beginning in May 2009. It is used to track contacts with offenders by a mental health professional,

\footnotetext{
${ }^{3}$ As some institutions report their data jointly on certain variables of interest, they were combined into one larger institution. Specifically, the annexes to Bowden and Drumheller institutions and the main institutions, the Regional Mental Health Centre and Archambault Institution in Quebec region, and the Regional Treatment Centre, Pacific Institution and Regional Reception and Assessment Centre in Pacific were combined due to one or more variables of interest collapsed across multiple sites.
} 
including the referral source, reason for referral, the type of service provided and the outcome. Data is input by front line staff and rolled up nationally using a reporting template in Excel developed by the author. Reports are provided to each institution four times a year including the number of contacts, the number of offenders served, and the reasons for contacts. The reasons for contacts have been grouped by CSC into those that have the primary aim to improve an offender's mental health through assessment and treatment (e.g. mental health assessments, counseling, medication monitoring and review) versus those which assess mental health primarily to inform operational decision making (e.g. psychological risk assessments, assessments for transfer, mental status assessments for segregated offenders, etc.). For the purpose of this study, the rate per 100 offenders of contacts for mental health and operational services and the percentage of offenders receiving these services were captured. For the purpose of calculating the percentage of offenders receiving services the flow-through population (i.e. the number of offenders who spent at least one day in the institution during the quarter) was used as the denominator. This population was calculated by taking the sum of the current population at the end of the quarter and the number of releases.

Corporate Reporting System. The Human Resources Reporting System is the official system for tracking all staffing actions and training within CSC. For the purpose of the current study, data that was previously extracted from this system and posted to CSC's internal Corporate Reporting System were used to obtain the number of staff in the institutions and the number of overtime hours. The number of staff were converted to a ratio per 100 inmates. Overtime hours were standardized per 100 full time staff. Additionally, a list of staff who attended a two day mental health training session was 
extracted from the HRMS system by CSC's corporate human resources branch and provided to the author. As staff movement during the quarters was not captured, it could not be confirmed that the staff who were trained remained in the institution at the end of the quarter. Given these limitations, and in the absence of an appropriate denominator, the number of staff receiving the training during the quarter was not standardized.

\section{Computerized Mental Health Intake Screening System (CoMHISS). This} system was fully implemented across CSC in an electronic version as of January 2010 (many sites began computerized testing prior to this date). CoMHISS involves offering mental health screening at intake to offenders admitted under a new Warrant of Committal to ensure timely identification of mental health issues. It was previously implemented in a paper and pencil version in February 2008 prior to the release of the computerized version (Stewart et al., 2010). A pilot project in one region also took place beginning in 2006. The screening includes three tests - the Brief Symptom Inventory (Derogatis, 1993), the Depression and Hopelessness Scale (Mills \& Kroner, 2003), and the Paulhus Deception Scales (Paulhus, 1998). Test lists were extracted from the computerized system for the recent tests, and databases that were maintained by CSC's research branch were used to obtain the list of offenders who completed the paper and pencil versions.

\section{Aggregation of Data}

All data were extracted from the system at the individual level and aggregated to the institution level $(n=52)$ for each of the 24 quarters. Counts were converted into rates per 100 inmates for continuous variables (e.g., incidents, program enrolments, visits) or percentages for categorical variables (e.g., age, ethnicity, reintegration potential). For 
those data which vary over the course of a quarter (e.g. demographic data for the sample, the current inmate population, staffing levels) snapshot data were taken on the last day of that quarter. For count data (e.g. incident rates), these were converted to rates per 100 inmates by dividing the count for the quarter (e.g. the number of incidents) by the population on the last day of the quarter and multiplying this by 100 .

\section{Measures}

Outcome variables in the current study were the rate of institutional incidents (e.g., self-harm, suicide, violence between inmates or on staff, drug incidents, damage to property, and disciplinary infractions; all extracted from the CSC/NPB Data Warehouse). Independent variables identified through previous research are listed in Table 3, along with the corresponding data sources. Individual factors that the study controlled for included demographic characteristics such as age, sentence length, and reintegration potential. These control variables were all extracted from the CSC/NPB Data Warehouse, and aggregated as categorical variables. Specifically, age was captured as the proportions of offenders who were 25 or younger, 26-40, 41-65 and older than 65. Reintegration potential ratings are completed by CSC staff, and fall within the categories of low, medium or high. Sentence lengths were grouped as less than 3 years, 3 to less than 5 years, 5 to less than 10 years, 10 years or more, or indeterminate/life sentences.

\section{Analyses}

The use of pooled time series analysis offers many advantages including a) increased statistical power with small sample sizes, b) differences between sampling units 
Table 3.

Institutional characteristics: measures and data sources.

\begin{tabular}{|c|c|c|}
\hline Characteristic & $\begin{array}{l}\text { Measure (hypothesized relationship direction } \\
\text { indicated in parentheses) }\end{array}$ & Source \\
\hline \multirow[t]{2}{*}{ Idling } & Number of program enrolments/100 inmates (-) & $\mathrm{DW}$ \\
\hline & Number of education enrolments/100 inmates (-) & $\mathrm{DW}$ \\
\hline Contact with family & Number of approved applications for visits/100 & DW \\
\hline and others & inmates (-) & \\
\hline \multirow[t]{6}{*}{ Staffing levels } & Number of overtime hours $/ 100$ staff $(+)$ & CRS/ \\
\hline & & HRMS \\
\hline & Total number of staff/100 inmates (-) & CRS/ \\
\hline & & HRMS \\
\hline & Number of health services staff $/ 100$ inmates $(-)$ & CRS/ \\
\hline & & HRMS \\
\hline Staff training on & Number of staff who received two day mental & HRMS \\
\hline mental health issues & health training during the quarter $(-)$ & \\
\hline Population & $\begin{array}{l}\text { Number of inmates in the institution on the last } \\
\text { day of the quarter }(+)\end{array}$ & DW \\
\hline Crowding & Inmate population - rated capacity $(+)$ & DW \\
\hline Population stability & $\begin{array}{l}\text { Total number of movements (intakes, releases } \\
\text { and transfers) } / 100 \text { inmates }(+)\end{array}$ & DW \\
\hline
\end{tabular}




\begin{tabular}{|c|c|c|}
\hline Characteristic & $\begin{array}{l}\text { Measure (hypothesized relationship direction } \\
\text { indicated in parentheses) }\end{array}$ & Source \\
\hline Ethnic diversity & $\begin{array}{l}\text { Ethnic breakdown of inmates as the \% White, } \\
\text { Black, Aboriginal, Asian and Other Ethnicity. (+ } \\
\text { with more ethnically diverse populations) }\end{array}$ & DW \\
\hline \multirow[t]{5}{*}{ Service provision } & $\begin{array}{l}\text { Number of mental health services provided } / 100 \\
\text { inmates (-) }\end{array}$ & PMHTD \\
\hline & $\%$ of inmates receiving mental health services (-) & PMHTD \\
\hline & $\begin{array}{l}\text { Number of operational focused mental health } \\
\text { services provided/100 inmates }(-)\end{array}$ & PMHTD \\
\hline & $\begin{array}{l}\% \text { of inmates at end of quarter who had received } \\
\text { operational focused mental health services } \\
\text { during the quarter (-) }\end{array}$ & PMHTD \\
\hline & $\begin{array}{l}\% \text { of population at end of quarter who had been } \\
\text { screened at intake for mental health issues (-) }\end{array}$ & CoMHISS \\
\hline
\end{tabular}

Note. CoMHISS $=$ Computerized Mental Health Intake Screening System, CRS $=$ Corporate Reporting System, HRMS $=$ Human Resources Management System, DW $=$ CSC/NPB Data Warehouse, PMHTD = Psychology and Mental Health Tracking Database. 
are absorbed by dummy variables ${ }^{4}$, "thereby limiting any substantive analysis to change over time, independent of individual differences" (Soliday, Moore \& Lande, 2002, p.71), and c) pooled time series analysis is more tolerant of missing data than traditional approaches, such as repeated measures ANOVA (Elgar, Waschbusch, McGrath, Stewart $\&$ Curtis, 2003). In the current study, the first two advantages of PTSA were most relevant given that complete data was available for all sites throughout the study period. However, by aggregating data to the institutional level, the sample size was relatively small $(n=52)$. Finally, from the author's experience in corrections there is a seemingly widespread belief (that does not appear to have been tested to date) that each institution is unique. Given this, it was expected that potentially large individual differences between sites would be observed, and would need to be controlled for.

Pooled time series analysis involves (1) pooling the data and estimating the regression model, (2) calculating the Durbin-Watson statistic (DW) which is then converted into an estimate of the correlation $(r)$ between adjacent residuals using the formula $r=(2-\mathrm{DW}) / 2,(3)$ transforming the dependent and independent variables to adjust for the correlation using the formulae $\mathrm{Y}^{\prime}=\mathrm{Y}_{\mathrm{t}}-r \mathrm{Y}_{\mathrm{t}-1}$ and $\mathrm{X}^{\prime}=\mathrm{X}_{\mathrm{t}}-r \mathrm{X}_{\mathrm{t}-1}$ where $\mathrm{t}$ represents the time at which the measure is taken, (4) conducting the regression analysis again on the transformed variables, and (5) re-examining correlations among residuals from this second analysis to ensure the transformation was successful [i.e. $r<.15$ is considered successful as per the recommendation of Ostrom (1990; cited in Elgar et al.,

\footnotetext{
${ }^{4}$ The number of dummy variables required is one less than the number of sampling units (Soliday et al, 2002). In the current study, 51 dummy variables were used.
} 
2003]. Consistent with the recommendations of the Soliday et al. (2002) review of the application of pooled time series analysis and its benefits, the Cochrane-Orcutt procedure described above was used to adjust for serial correlation. A more in depth review of this and other approaches for transforming data to adjust for serial correlation is provided by Kutner, Nachtscheim, Neter and $\operatorname{Li}(2005, \mathrm{Ch} .12)$. The PTSA and descriptive analyses were conducted using PASW Statistics (version 18), with the use of Microsoft Excel 2007 to conduct the required transformations of the data.

\section{Results}

\section{Collinearity and Other Statistical Assumptions}

Data were screened for general assumptions (e.g. normality, outliers) and no violations were noted, with the exception of a strong positive skew for the incident rate variables. Square root and $\log$ transformations were attempted, but as the general pattern of findings were highly similar, the untransformed data was retained for ease of interpretation. Other statistical assumptions - notably independence of errors - were tested and controlled for within the context of PTSA, as discussed below. Given the large number of potential predictors, and that many were potentially related to one another, it was expected that the assumption of collinearity would be violated. As such, a correlation matrix of all possible variables was examined prior to conducting PTSA. Where variables were correlated with an $r=.6$ or greater, this was addressed by either creating a composite variable of the highly related variables, or one or more variables were excluded from the model. Specifically, four types of incidents - self-injury, violence towards others, property damage, and other incidents - were summed to create a nondrug related incident category. A separate model was built to predict drug related 
incidents. The proportion of offenders receiving mental health services, and rate of mental health contacts per 100 offenders were both highly correlated with the number of staff $(r \mathrm{~s}=.61$ and .60 respectively). Given that these data were only available for approximately one year, and there was substantial missing data within that year, they were excluded from the analyses. This allowed for a larger sample size due to the fact that PTSA excludes all observations for which there is not complete data on all variables. Given that the rate of both program and education enrolments and completions were highly correlated, only enrolments were included in the model.

For the categorical variables (i.e. age, ethnicity, and reintegration potential), it was necessary to exclude the proportions for at least one level to avoid having a singular data matrix whereby one variable was a perfect linear combination of two or more other variables. To determine which levels to exclude, a two-step process was followed. First, the levels that were of greatest interest to the research question (e.g. low reintegration potential offenders) and/or CSC priorities (e.g. Aboriginal offenders, shorter sentences, etc.; CSC, 2009b, 2009c) were chosen for inclusion. Following this, any variable that was correlated above .6 with the already included levels was excluded, and the remaining levels were retained in the model.

\section{Descriptive Analyses}

Descriptive statistics for all variables aggregated by site (i.e. ignoring the time dimension, and taking the average value over the six year follow-up), including those excluded from the PTSA analyses are presented in Table 4 . The data were also compared by security level (see Table 5) using one-way ANOVAs with post-hoc Tukey tests. This approach was necessary to analyze the impact of the security levels of the institutions, 
Table 4.

Sample descriptive statistics for all sites $(n=52)$.

\begin{tabular}{|c|c|c|c|c|}
\hline & Min & $\operatorname{Max}$ & $\vec{M}$ & $S D$ \\
\hline Rated capacity & 35.50 & 598.00 & 273.16 & 154.86 \\
\hline Population & 28.83 & 604.92 & 263.22 & 160.04 \\
\hline Crowding & -151.17 & 102.21 & -9.94 & 47.63 \\
\hline Intakes & 10.25 & 383.88 & 91.33 & 75.32 \\
\hline Departures & 10.96 & 357.00 & 81.02 & 75.67 \\
\hline Total Movement & 25.59 & 201.30 & 66.85 & 33.55 \\
\hline Low RP & 3.00 & 90.54 & 36.29 & 25.03 \\
\hline Young inmates & 1.92 & 31.08 & 14.42 & 8.22 \\
\hline Short sentences & 8.88 & 59.42 & 29.61 & 12.06 \\
\hline Programs & .00 & 240.17 & 36.48 & 39.12 \\
\hline Education & .00 & 164.51 & 44.40 & 28.97 \\
\hline Inmate employment & .00 & 371.29 & 216.75 & 73.21 \\
\hline Staff & 1.19 & 252.79 & 107.93 & 52.31 \\
\hline Overtime/100 staff & 455.43 & 3884.29 & 1705.35 & 788.86 \\
\hline Staff $M H$ training & .00 & 12.67 & 3.03 & 2.93 \\
\hline MH intake screen & 2.00 & 26.63 & 9.30 & 5.28 \\
\hline Aboriginal & 2.08 & 95.79 & 23.74 & 23.46 \\
\hline Visits & 34.38 & 1226.29 & 305.84 & 245.32 \\
\hline
\end{tabular}




\begin{tabular}{lcccc}
\hline & Min & Max & $M$ & $S D$ \\
\hline Asian & 0.00 & 10.38 & 2.86 & 2.70 \\
Other ethnicity & 0.25 & 6.33 & 2.88 & 1.38 \\
Non-drug incidents & .32 & 135.22 & 17.12 & 22.36 \\
Drug incidents & .22 & 15.24 & 4.09 & 3.84 \\
Note. $\mathrm{RP}$ = Reintegration Potential, MH = mental health. Other ethnicity is all ethnicities \\
other than White, Black, Aboriginal or Asian.
\end{tabular}


Table 5.

Sample descriptive statistics by security level.

Security Level

\begin{tabular}{|c|c|c|c|c|c|c|c|c|}
\hline & \multicolumn{2}{|c|}{$\begin{array}{l}\text { Minimum } \\
(\mathrm{n}=15)\end{array}$} & \multicolumn{2}{|c|}{$\begin{array}{l}\text { Medium } \\
(\mathrm{n}=17)\end{array}$} & \multicolumn{2}{|c|}{$\begin{array}{l}\text { Maximum } \\
(\mathrm{n}=8)\end{array}$} & \multicolumn{2}{|c|}{$\begin{array}{l}\text { Multilevel } \\
(\mathrm{n}=12)\end{array}$} \\
\hline & $\bar{M}$ & SD & $\mathrm{M}$ & $\mathrm{SD}$ & $M$ & SD & $\mathrm{M}$ & $\mathrm{SD}$ \\
\hline Rated capacity & $175.97^{\mathrm{a}}$ & 88.68 & $414.12^{b}$ & 102.91 & $277.59^{\mathrm{a}}$ & 72.85 & $192.01^{\mathrm{a}}$ & 177.78 \\
\hline Population & $156.60^{\mathrm{a}}$ & 81.22 & $411.39^{b}$ & 109.99 & $283.38^{a, b}$ & 99.43 & $173.14^{\mathrm{a}}$ & 167.01 \\
\hline Crowding & $-19.37^{\mathrm{a}}$ & 31.41 & $-2.73^{\mathrm{a}}$ & 62.87 & $5.78^{\mathrm{a}}$ & 66.68 & $-18.86^{\mathrm{a}}$ & 14.70 \\
\hline Total movement & $63.50^{\mathrm{a}}$ & 17.42 & $55.84^{\mathrm{a}}$ & 19.26 & $85.67^{\mathrm{a}}$ & 60.77 & $74.07^{\mathrm{a}}$ & 37.76 \\
\hline Low RP & $7.04^{\mathrm{a}}$ & 2.62 & $42.66^{\mathrm{b}}$ & 10.05 & $69.19^{c}$ & 19.56 & $41.91^{b}$ & 21.28 \\
\hline Young inmates & $7.84^{\mathrm{a}}$ & 4.87 & $16.11^{\mathrm{b}}$ & 8.82 & $20.40^{b}$ & 7.81 & $16.28^{\mathrm{b}}$ & 6.17 \\
\hline Short sentences & $31.27^{\mathrm{a}}$ & 12.26 & $27.45^{\mathrm{a}}$ & 8.32 & $21.78^{\mathrm{a}}$ & 13.73 & $35.80^{\mathrm{a}}$ & 12.83 \\
\hline
\end{tabular}


Security Level

\begin{tabular}{|c|c|c|c|c|c|c|c|c|}
\hline & \multicolumn{2}{|c|}{$\begin{array}{l}\text { Minimum } \\
(\mathrm{n}=15)\end{array}$} & \multicolumn{2}{|c|}{$\begin{array}{l}\text { Medium } \\
(\mathrm{n}=17)\end{array}$} & \multicolumn{2}{|c|}{$\begin{array}{l}\text { Maximum } \\
(\mathrm{n}=8)\end{array}$} & \multicolumn{2}{|c|}{$\begin{array}{l}\text { Multilevel } \\
(\mathrm{n}=12)\end{array}$} \\
\hline & $\mathrm{M}$ & SD & $\mathrm{M}$ & SD & $\bar{M}$ & SD & $\mathrm{M}$ & SD \\
\hline Programs & $54.84^{\mathrm{a}}$ & 59.89 & $25.53^{\mathrm{a}}$ & 8.66 & $10.70^{b}$ & 4.82 & $46.22^{\mathrm{a}}$ & 34.27 \\
\hline Education & $40.33^{\mathrm{a}}$ & 17.00 & $41.31^{\mathrm{a}}$ & 11.15 & $38.56^{\mathrm{a}}$ & 21.27 & $57.75^{\mathrm{a}}$ & 52.90 \\
\hline Inmate employment & $261.73^{a}$ & 48.13 & $228.49^{\mathrm{a}, \mathrm{b}}$ & 44.40 & $166.49^{b}$ & 58.96 & $177.38^{b}$ & 101.59 \\
\hline Visits & $500.23^{\mathrm{a}}$ & 336.53 & $261.04^{a, b}$ & 151.25 & $168.42^{b}$ & 88.48 & $217.94^{b}$ & 140.84 \\
\hline Staff & $84.16^{\mathrm{a}}$ & 32.54 & $81.38^{\mathrm{a}}$ & 16.54 & $116.41^{\mathrm{a}}$ & 52.58 & $169.61^{\mathrm{b}}$ & 55.85 \\
\hline Overtime/100 staff & $843.95^{\mathrm{a}}$ & 249.69 & $1777.70^{b}$ & 557.02 & $2424.33^{\mathrm{c}}$ & 572.70 & $2200.29^{b, c}$ & 694.81 \\
\hline Staff MH Training & $0.56^{\mathrm{a}}$ & 0.52 & $2.64^{\mathrm{a}}$ & 3.06 & $5.44^{\mathrm{c}}$ & 2.64 & $5.05^{\mathrm{c}}$ & 2.02 \\
\hline MH intake screening & $9.92^{\mathrm{a}}$ & 4.08 & $9.97^{\mathrm{a}}$ & 5.14 & $8.15^{\mathrm{a}}$ & 5.78 & $8.32^{\mathrm{a}}$ & 6.73 \\
\hline Aboriginal & $27.14^{\mathrm{a}}$ & 32.08 & $17.79^{\mathrm{a}}$ & 14.07 & $17.54^{\mathrm{a}}$ & 12.17 & $32.06^{\mathrm{a}}$ & 26.19 \\
\hline
\end{tabular}


Security Level

\begin{tabular}{|c|c|c|c|c|c|c|c|c|}
\hline & \multicolumn{2}{|c|}{$\begin{array}{l}\text { Minimum } \\
(\mathrm{n}=15)\end{array}$} & \multicolumn{2}{|c|}{$\begin{array}{l}\text { Medium } \\
(\mathrm{n}=17)\end{array}$} & \multicolumn{2}{|c|}{$\begin{array}{c}\text { Maximum } \\
(\mathrm{n}=8)\end{array}$} & \multicolumn{2}{|c|}{$\begin{array}{c}\text { Multilevel } \\
(\mathrm{n}=12)\end{array}$} \\
\hline & $\mathrm{M}$ & $\overline{\mathrm{SD}}$ & $\bar{M}$ & SD & $\mathrm{M}$ & SD & $\mathrm{M}$ & $\mathrm{SD}$ \\
\hline Asian & $3.79^{\mathrm{a}}$ & 3.31 & $3.09^{\mathrm{a}}$ & 2.65 & $2.18^{a}$ & 2.45 & $1.81^{\mathrm{a}}$ & 1.75 \\
\hline Other ethnicity & $2.53^{\mathrm{a}}$ & 1.83 & $3.08^{\mathrm{a}}$ & 1.16 & $3.16^{\mathrm{a}}$ & 0.98 & $2.82^{\mathrm{a}}$ & 1.30 \\
\hline Non-drug incidents & $4.63^{\mathrm{a}}$ & 5.18 & $14.65^{\mathrm{a}, \mathrm{b}}$ & 13.65 & $24.59^{\mathrm{a}, \mathrm{b}}$ & 14.38 & $31.26^{\mathrm{b}}$ & 37.42 \\
\hline Drug incidents & $1.52^{\mathrm{a}}$ & 1.13 & $6.05^{b}$ & 4.57 & $6.69^{b}$ & 3.72 & $2.79^{\mathrm{a}, \mathrm{b}}$ & 2.45 \\
\hline
\end{tabular}

Note. Common superscript letters are used to indicate security levels that do not significantly differ (based on results of post-hoc

Tukey's tests) from one another on the variable of interest. All variable definitions are the same as in Table 4. 
given that this could not be tested within the context of PTSA. Given that dummy variables for security level were singular with the institutional dummy variables required to absorb individual difference under this approach, a PTSA model accounting for the aggregate effect of security level was not possible. As can be seen in the tables, there was considerable variability in almost all measures, both across security levels (i.e. almost all variables differed significantly between security levels) and within them (i.e. most variables had large standard deviations and wide ranges). In general terms, medium and multilevel institutions were highly similar on almost all variables, other than the fact that medium security institutions were larger (i.e. had larger rated capacities and total populations). However, multilevel security institutions had higher staffing ratios per 100 inmates and higher rates of staff mental health training.

Maximum security institutions had significantly higher risk profile offenders (e.g. more offenders rated low reintegration potential, more younger offenders, and more long sentences) and minimum security institutions had lower risk populations. Unexpectedly, the rate of program enrolments per 100 inmates was significantly lower in maximum security institutions than in minimum security institutions. It is also noteworthy, that although the total ratio of staff per 100 inmates was higher in maximum security institutions than in medium or minimum security sites, these differences only approached statistical significance. It is not surprising then, given the higher risk population they work with, that staff in maximum security institutions worked significantly more overtime hours per 100 staff, than did staff in minimum and medium security institutions. In spite of these differences between institutions, non-drug incident rates per 100 inmates did not differ between most security levels, with the exception that there were 
significantly more incidents in multilevel institutions than in minimum security sites. While the direction of the differences between varying security levels was in line with expectations (e.g. maximum security had more incidents on average than medium security, which in turn had more incidents on average than minimum security institutions) none of these differences were statistically significant. The pattern of results for drug related incidents was considerably different. That is there were significantly fewer drug incidents in minimum security institutions compared to medium or maximum security institutions. No differences were observed between medium and maximum security institutions. The lower rate of drug incidents in multilevel institutions compared to medium and maximum security institutions approached statistical significance $(p=$ .052 and .056 respectively).

\section{Pooled Time Series Analyses}

Variance in incidents explained by the models. The first step in PTSA involved controlling for the effects of serial dependence. For both the models predicting non-drug and drug incidents, one iteration was sufficient to reduce serial dependence to below the $r$ $<.15$ threshold. As seen in Table 6 the institutional characteristics significantly contributed to the prediction of both types of incidents. As indicated by the $R^{2}$ change values for each block, institutional differences accounted for a substantial proportion of variation in both non-drug (64\%) and drug (67\%) incidents, with the risk related control variables accounting for little additional variance (i.e. they accounted for less than $1 \%$ in both models as the values in the table are rounded up). The institutional characteristics input in the third block accounted for more incremental variance in non-drug incidents (5\%), than in drug incidents (1\%). By summing the $R^{2}$ change values, it can be seen that 
Table 6 .

PTSA results of incidents regressed on predictor variables

\begin{tabular}{|c|c|c|c|c|c|c|c|c|}
\hline & \multicolumn{4}{|c|}{ Non-drug incidents } & \multicolumn{4}{|c|}{ Drug incidents } \\
\hline & $\begin{array}{c}\Delta \mathrm{Adj} . \\
R^{2}\end{array}$ & $b$ & $\mathrm{SE}$ & $p$ & $\begin{array}{c}\Delta \mathrm{Adj} . \\
R^{2}\end{array}$ & $b$ & $\mathrm{SE}$ & $p$ \\
\hline $\begin{array}{l}\text { Block 1: Indicator } \\
\text { variables }^{\mathrm{a}}\end{array}$ & $.64^{*}$ & & & $<.01$ & $.67 *$ & & & $<.01$ \\
\hline $\begin{array}{l}\text { Block 2: Control } \\
\text { variables }\end{array}$ & $.01 *$ & & & $<.01$ & $.01 *$ & & & $<.01$ \\
\hline Low RP & & $.52^{*}$ & .12 & $<.01$ & & $.10^{*}$ & .02 & $<.01$ \\
\hline Young inmates & & .02 & .15 & .92 & & .04 & .03 & .20 \\
\hline Short sentences & & .38 & .11 & $<.01$ & & .04 & .02 & .08 \\
\hline Block 3: & $.06 *$ & & & $<.01$ & $.01 *$ & & & $<.01$ \\
\hline $\begin{array}{l}\text { Institutional } \\
\text { characteristics }\end{array}$ & & & & & & & & \\
\hline Crowding & & $.08^{*}$ & .02 & $<.01$ & & -.00 & .00 & .49 \\
\hline Total movements & & $.08^{*}$ & .03 & $<.01$ & & -.00 & .01 & .70 \\
\hline Education & & -.01 & .03 & .76 & & -.01 & .01 & .52 \\
\hline Inmate employment & & -.01 & .01 & .93 & & .00 & .00 & .99 \\
\hline Visits & & .00 & .01 & .46 & & .00 & .00 & .21 \\
\hline Staff/100 inmates & & $.43^{*}$ & .03 & $<.01$ & & $.02 *$ & .01 & $<.01$ \\
\hline
\end{tabular}




\begin{tabular}{|c|c|c|c|c|c|c|c|c|}
\hline & \multicolumn{4}{|c|}{ Non-drug incidents } & \multicolumn{4}{|c|}{ Drug incidents } \\
\hline & $\begin{array}{c}\Delta \mathrm{Adj} . \\
R^{2}\end{array}$ & $b$ & SE & $p$ & $\begin{array}{c}\Delta \text { Adj. } \\
R^{2}\end{array}$ & $b$ & SE & $p$ \\
\hline Programs & & $-.04 *$ & .02 & .04 & & .00 & .00 & .62 \\
\hline Overtime $/ 100$ staff & & .00 & .00 & .36 & & .00 & .00 & .16 \\
\hline Staff $\mathrm{MH}$ training & & -.06 & .03 & .07 & & .00 & .01 & .96 \\
\hline MH intake screening & & -2.84 & 4.08 & .49 & & .59 & .79 & .46 \\
\hline Aboriginal & & -.27 & .16 & .09 & & $-.08 *$ & .03 & .01 \\
\hline Asian & & -.32 & .34 & .36 & & -.09 & .07 & .22 \\
\hline Other ethnicity & & -.36 & .40 & .37 & & -.14 & .08 & .09 \\
\hline
\end{tabular}

Note. $\mathrm{RP}=$ Reintegration Potential; $\mathrm{MH}=$ mental health; other ethnicity includes all ethnicities other than White, Black, Aboriginal and Asian.

${ }^{2} 51$ indicator variables were entered for 51 of the institutions to absorb differences between institutions following the steps of PTSA (Soliday et al., 2002).

$* \mathrm{p}<.05$

the full models accounted for approximately $71 \%$ of variance in non-drug incidents and $69 \%$ of variance in drug incidents.

Significant predictors of incidents. Table 6 also presents the coefficients for each predictor input in the model, excluding the institutional indicator variables for space reasons. As seen in the table, among the block 2 control variables, only the proportion of offenders rated low reintegration potential (RP) significantly predicted incident rates, in the case of both non-drug and drug related incidents. The proportion of offenders serving short (i.e. less than three year) sentences, was related with significantly more non-drug 
incidents. For drug incidents, this positive relationship between the proportion of short sentences and incidents only approached statistical significance. Among the institutional characteristics, the predictors of incidents varied by type of incident, and as such they are discussed separately below. It should be noted that while the control and institutional characteristics variables were tested for multicollinearity as part of the data screening discussed previously, this assumption was violated once they were entered in the PTSA model. With the inclusion of the institutional indicator variables required to control for individual site differences in PTSA, all individual and environmental variables, except for staff training on mental health and the percentage of inmates screened for mental health at intake, had tolerance values less than 0.2 and variance inflation factor (VIF) values that approached or exceeded 10 (Tabachnick \& Fidell, 2007).

In other words, the control and institutional characteristic variables were highly correlated with the institutional indicator variables ${ }^{5}$. This is not entirely surprising given the breadth of knowledge and theory that guided the selection of these variables as potential predictors of inmate adjustment. Indeed, it is often these characteristics that are used to describe differences between institutions, which is also evident when considering the differences between the various security levels at the descriptive level. Given this, the coefficients should be interpreted cautiously, as they represent the unique contribution of that predictor when holding all other predictors in the model (including the indicator variables) constant.

\footnotetext{
${ }^{5}$ This interpretation was also confirmed by running linear regression models regressing each of the multicollinear independent variables on the 51 institutional indicator variables. Adjusted $R^{2}$ values for these models ranged from 0.56 to 0.98
} 
Non-drug incidents. As seen in Table 6, four institutional characteristics were significantly related to the number of non-drug incidents. Specifically crowding, total movement rates, and higher staffing ratios were positively associated with non-drug incident rates. Conversely, higher rates of program enrolment were inversely associated with non-drug incident rates. Also noteworthy, were inverse relationships that approached statistical significance between the number of staff trained on mental health $(p=.07)$, and the proportion of Aboriginal offenders $(p=.09)$ with incident rates.

Drug incidents. Given that the institutional characteristic variables accounted for considerably less variance in drug incidents, it is unsurprising that only the total number of staff and the proportion of Aboriginal inmates were related to the rate of drug incidents in the quarter during which they were measured. As was the case in the prediction of nondrug incidents, there was a positive relationship between staffing ratios and drug related incidents. The proportion of Aboriginal inmates was inversely related to drug related incidents.

\section{Discussion}

While the potential implications of the findings as discussed below should be viewed as speculative and requiring further research to confirm the proposed explanations, the current study supports the consideration of institutional characteristics to explain inmate adjustment to incarceration. The exact incremental validity that these factors contribute is somewhat unclear, given that as discussed previously, over $60 \%$ of the variance in institutional incidents was accounted for by individual differences between institutions. Given that a great deal of these individual differences are likely due to the variables considered in the model, it is not possible to tease these unique effects 
apart as accurately as initially planned. Nonetheless, when considering the differences at a descriptive level between institutions of varying security level, and cautiously interpreting the regression coefficients from the PTSA model some interesting findings emerge. By the same token, those predictors - or the theories upon which they were selected - that were not significant in the PTSA models should not be immediately disregarded given the extent to which the vast majority of variables were highly multicollinear with the institutional indicator variables. Given this, the variables that were non-significant (age, education, employment, visits, overtime, mental health screening at intake and the proportions of Asian and other ethnicity inmates) are not discussed in detail below. While these non-significant findings would be of interest if replicated in future research, it would be ill-advised to make definite statements about their relationships with institutional adjustment given the threats to the validity of the PTSA models. In fact, many of these variables (e.g. age, overtime, and employment) varied significantly across security levels, as did incident rates. Given that a past meta-analysis found relationships between factors such as age, employment and education with prison misconduct (Gendreau, Goggin \& Law, 1997) the non-significant relationships were surprising.

When considering the significant relationships in this study, given the risk of committing an ecological fallacy, the findings should not be used to information decisions about individual inmates. They should be seen as environmental characteristics that may interact with individual differences to impact inmate adjustment to incarceration (Andrews \& Bonta, 2010). In other words, simply improving an aspect of the prison environment will not necessarily address the root causes of institutional adjustment issues 
among particular inmates. Considered within the social capital framework, this point can best be conceptualized through the distinction between structural and cognitive dimensions of social capital. That is simply altering the physical elements of the environment can only have meaningful impacts on the outcome of interest - in this case incident rates - if inmates and staff perceive these as meaningful improvements to the environment and if they address the underlying causes of the behaviours. Given that one limitation of the current study was that it was not possible to operationalize the cognitive components of social capital, future research is needed to test this hypothesis.

\section{The Relationship Among Incident Types}

Given that substance use is a strong predictor of institutional misconduct and crime more generally (Andrews \& Bonta, 2010; Bonta, Law \& Hanson, 1998), it was hypothesized that an index combining all incidents would be an appropriate measure of institutional adjustment. However, drug incidents were not as highly correlated with the non-drug incidents as was expected. In the context of PTSA different predictors of these two incident types emerged, with the factors considered accounting for more variance in non-drug than drug incidents. It is unclear why patterns of drug related incidents were different from those of non-drug incidents, although this may reflect the introduction of an indoor tobacco ban in 2006 followed by a total smoking ban in 2008 (CSC, 2007). This finding could also reflect the fact that some substances which are illegal within CSC (including tobacco and alcohol) are legal in the community. On the other hand many of the non-drug incidents would be illegal in either setting. Thus, efforts to manage inmates and rehabilitation efforts might be more heavily directed towards these behaviours that must be addressed for inmates to successfully reintegrate into the community at the 
completion of their sentence. Finally, there may be differing priorities and/or preoccupations across security levels that lead staff to be more or less vigilant to certain types of infractions. For example, staff may be more alert to and more likely to document the non-drug related (and in particular violent) incidents.

\section{Capacity to Detect and Respond to Incidents}

Consistent with the notion of collective efficacy within the social capital framework, the positive relationship between the total number of staff and incident rates of either type might reflect an increased capacity to detect rule infractions. Alternatively, this may reflect that additional staff are hired in response to increasing rates of incidents in an institution to enhance the capacity to prevent these incidents. If this were the case it should be considered that increasing staffing to return to previous staffing ratios will not guarantee reducing incident rates, as it would likely require additional staff beyond this to address the causes behind the increases. Thus it is more likely that increases in staffing levels simply prevent further increases rather than reduce incident rates to previous levels. This possibility is one that all agencies should consider, as often times funding increases appear to attempt to return levels of service to a level that was previously adequate, with the expectation that this will improve outcomes to this previous level. Furthermore, it is important to consider the functions and roles of the added staff. For example, while maximum security institutions had slightly higher staff to inmate ratios, the rates of program enrolments were significantly lower in these sites. Programs would be of greatest value in maximum security institutions according to Andrews and Bonta's (2010) risk principle. However, this finding may reflect the fact that increases in staffing are tied more to security concerns and responding to higher incident rates, with less time 
and resources available for staff to run programs and address the causes behind higher incident rates.

\section{Capacity to Respond to Cultural Differences}

The finding that an increased proportion of Aboriginal offenders was significantly related to fewer drug incidents, along with a trend in the same direction for non-drug incidents, may be in part related to CSC's priority to enhance capacity to respond to the needs of Aboriginal offenders (who are over-represented in federal incarcerated populations; CSC, 2010). Specifically, in those areas where the proportion of incarcerated Aboriginals is higher, it is likely that there is also a higher proportion of Aboriginals in that same community. Therefore, there may be more resources to draw from in that community to both recruit staff or to consult with in developing strategies to respond to the particular needs of Aboriginal offenders. Alternatively, where the proportion of Aboriginal offenders is higher there may be a greater degree of bonding social capital among inmates and bridging social capital between inmates and staff, as a result of an enhanced perception of cultural awareness and understanding and shared values.

Given that the relationships between the proportion of Asian and other ethnic groups were also negatively related to incident rates (although not significantly so), it would be interesting to explore this area further. Unfortunately data on staff ethnicity is not collected by CSC to enable comparisons between the ethnic breakdowns of staff and inmates (c.f. McCorkle et al., 1995). It is likely, however, given CSC's emphasis on capacity to respond to Aboriginal offenders that there may be more staff who are aware of their particular needs, thus creating an environment which is higher in bridging social capital. Thus, all inmates may develop bonding social capital with others of a similar 
ethnic background. However, bridging social capital may be less consistently developed in sites with greater proportions of minority ethnic groups that have received less attention in CSC due to the fact they represent a smaller proportion of the overall inmate population. Future research assessing both inmate and staff perspectives on this issue appear warranted to explore this finding in greater detail.

Regardless of the explanation for this finding, it should be interpreted being mindful of the previously discussed concept of ecological fallacies. It should not be used to inform placement decisions solely on the basis of an individual's ethnicity. While in a very small number of cases, ethnicity does inform placements in CSC (e.g. the transfer of offenders to Aboriginal healing lodges in Pacific and Prairie regions), generally speaking these trends observed are naturally occurring. Removing an offender from an institution which is closer to his or her home community or which is better suited to provide necessary programming is for obvious reasons not recommended. Rather, it would be preferable to look to these sites with higher proportions of minority ethnic groups to learn which practices are most effective in working with these offenders.

\section{Capacity to Address Criminogenic Risk Factors}

In line with the coping/adaption theory discussed at the outset of this paper, the finding that higher program enrolment rates were associated with fewer non-drug incidents was unsurprising. This finding would appear to reflect CSC's reputation as a world leader in correctional programming. It is interesting, however that this effect was observed despite the fact that at an aggregate level the rates of programming were highest in sites with the lowest risk offenders (i.e. the minimum security institutions) and lowest in the sites with highest risk offenders (i.e. the maximum security sites). Whether an even 
larger effect could achieved by re-visiting the allocation of programming resources to ensure that programming is offered to those with the highest risks and needs (c.f. Andrews \& Bonta, 2010), could be explored further by both CSC and future research.

It is somewhat unclear as to why the same effect was not observed for the drug related incidents. One potential explanation may stem from the fact that addressing substance use and addictions is a lengthy process, with relapse expected under the wellknown transtheoretical stages of change model (Prochaska, DiClemente \& Norcross, 1992). Given this, it is perhaps unrealistic to expect immediate reductions in institutional incidents related to substance use. Finally, given CSC's renewed commitment to keeping drugs out of its institutions as part of its Transformation Agenda (CSC, 2009c), enforcement practices may have fluctuated over the six year period which potentially confounded the results.

\section{The Impact of Crowding}

As discussed previously in the context of the deprivation theory of inmate adjustment, the relationship between crowding and incident rates has been highly contested. The current findings suggest that crowding is related to increased rates of institutional incidents. While specific interactions were not tested, it is noteworthy that incident rates as expected were highest in maximum security institutions. This was the only security level with a mean population that exceeded the rated capacity and the greatest proportion of younger offenders (i.e. under the age of 25) was found in maximum security facilities. This is somewhat consistent with the fact that as previously discussed the effect of crowding is most likely where the population is younger (Franklin et al., 2006). As CSC currently faces significant pressures due to a rapidly increasing 
population following changes to crime legislation, understanding how to best manage increasingly crowded institutions appears to be of considerable importance.

\section{Population Stability and Institutional Incidents}

In its Transformation Agenda and other documents (CSC, 2009b; 2009c), CSC has acknowledged challenges associated with a changing offender population, where the proportion of offenders serving short sentences has increased. In the current study, the proportion of short sentences was related to higher rates of non-drug institutional incidents. As CSC (2009c) notes, shorter sentences reduce the amount of time available to provide correctional programming to address criminogenic needs, which may offer part of the explanation for this finding. However, given that the effect observed is above and beyond any shared variance within programming enrolments, it appears that short sentences have other impacts on institutional adjustment beyond merely reducing the amount of time available to participate in programs. The emphasis of social capital on relationships may explain this, as shorter sentences leave less time for inmates to develop relationships with other inmates (or to build bonding social capital) and staff (bridging social capital). In the absence of strong (and positive) relationships, there may be less incentive for inmates and staff to work together to improve the institutional environment.

Related to this is the fact that high rates of movement may also impede the development of relationships. Future research is needed to rule out the alternative explanations that this movement is entirely a result of rather than a cause of institutional incidents. For example, inmates may be more likely to be transferred to other institutions, including treatment centres for those with mental health needs, or higher security level institutions, where their behaviour is problematic. Future research could consider these 
various explanations, by considering the frequency at which offender movements follow incidents, and by assessing the quantity and quality of relationships among inmates and staff through direct observation, surveys, and/or interviews.

\section{Staff Capacity to Respond to Mental Health Issues}

Given CSC's priority to enhance capacity to respond to mental health needs of offenders, the marginally significant inverse relationship between the number of staff who attended the two day mental health training and non-drug incident rates is encouraging. To date, $\mathrm{CSC}$ has prioritized training correctional officers at treatment centres, women's and maximum security institutions, which had the highest rates of incidents (treatment centres and women's institutions made up the majority of the mixed security level institutions). As the training continues to be delivered to all sites, greater improvements may be seen. Whether this training succeeded in addressing stigma and negative attitudes towards offenders with mental disorder (c.f. Bowers et al., 2006;

Callahan, 2004; Lavoie et al., 2006) and/or developed staff skills to work more effectively with this group (c.f. Motiuk \& Porporino, 1994) is beyond the scope of the current study, but warrants further exploration. It may be that sites where the training had a larger effect in terms of changing attitudes and behaviours had greater reductions in incident rates following training than those sites where training benefits were more modest.

\section{Limitations and Future Directions}

Given the previous comments about the analytical challenges encountered (e.g. multicollinearity among predictor variables and a high proportion of variance in incidents accounted for by individual site differences), it bears repeating that the findings in 
relation to specific predictors discussed above should be interpreted cautiously. In light of the risk of ecological fallacies, it would be prudent for future research to consider how these variations in institutional characteristics impact on individual offenders' outcomes. That is, as an offender moves from one institution to another, do his or her behaviours change? For example, does an Aboriginal offender who transfers to an institution with a greater proportion of Aboriginal offenders show better adjustment upon arriving at his new site? Does an offender rated as low reintegration potential adjust better upon transferring to a site with greater program offerings and/or which is less crowded? Positive answers to these questions which largely reflect the governance approach (Dilulio, 1987) discussed at the outset of this study, would support that management decisions may lead to better outcomes across the population as a whole.

Answering these individual level questions is necessary to inform case management practices for any particular offender. The use of multilevel modelling has been recommended to better address these questions (c.f. Lahm, 2008; Sampson et al., 1997). In the current study, individual level data was not analyzed for ethical reasons, primarily related to protecting the anonymity of offenders given that consent was not obtained to review their files as this study relied on secondary data files intended primarily for non-research purposes. Furthermore, linkage between databases on individual variables was not always possible due to the lack of a consistent identifier across databases. In spite of these limitations, this study is one of the few to include repeated measures over a six year period, thus to some extent addressing the limitations of previous cross-sectional research. 
More in depth consideration of their implications and/or replication of the findings is necessary prior to making significant changes to the operation of correctional institutions on the basis of this study. While many findings were likely unsurprising, this study represents one of the few standardized comparisons across security levels which revealed some particularly surprising results in terms of how resources are allocated within CSC. While it has long been believed that incident rates and problem behaviours are more common in higher security institutions, this study helps shed some light on potential institutional characteristics that could be targeted in an attempt to minimize these differences. Most notably, ensuring that programs, staffing and other resources are proportionate to the level of risk of the offenders that reside within these institutions appears to be a strategy worth exploring.

While a great deal of research has focused on individual risk factors in light of Andrews and Bonta's (2010) warning about the potential for ecological fallacies, even they acknowledge the value of social factors in certain situations. The current study identified correlates of institutional adjustment that are central to each of the deprivation (e.g. crowding), management (e.g. programming, staff training on mental health) importation (e.g. reintegration potential, and to a lesser extent age and ethnicity), coping/adaptation (e.g. programming) and social capital (e.g. staffing levels and programming as proxies of community capacity) theories. Integrating these various frameworks offers the potential for a more powerful and comprehensive explanation of inmate adjustment to incarceration and to reconcile conflicting findings of past research that have examined these theories in isolation. 


\section{References}

Andrews, D.A., \& Bonta, J. (2010). The psychology of criminal conduct $\left(5^{\text {th }}\right.$ ed.). New Providence, NJ: LexisNexis.

Angermeyer, M.C., Cooper, B., \& Link, B.G. (1998). Mental disorder and violence: Results of epidemiological studies in the era of de-institutionalization. Social Psychiatry and Psychiatric Epidemiology, 31, S1-S6.

Applebaum, K.L., Hickey, J.M., \& Packer, I. (2001). The role of correctional officers in multidisciplinary mental health care in prisons. Psychiatric Services, 52, 13431347.

Arsenault, L., Moffitt, T., Caspi, A., Taylor, P., \& Silva, A. (2000). Mental disorder and violence in a total birth cohort. Archives of General Psychiatry, 57, 979-986.

Baskin, D.R., Sommers, I., \& Steadman, H.J. (1991). Assessing the impact of psychiatric impairment on prison violence. Journal of Criminal Justice, 19, 271-280.

Bonta, J., \& Gendreau, P. (1990). Reexamining the cruel and unusual punishment of prison life. Law and Human Behavior, 14, 347-372.

Bonta, J., Law, M., \& Hanson, K. (1998). The prediction of criminal and violent recidivism among mentally disordered offenders: A meta-analysis. Psychological Bulletin, 123, 123-142.

Bottoms, A.E. (1999). Interpersonal violence and social order in prisons. In M. Tonry \& J. Petersilia (Eds.) Crime and justice: A review of research (Vol. 26). Chicago: The University of Chicago Press. 205-282.

Bowers, L., Carr-Walker, P., Allan, T., Callaghan, P., Nijman, H., \& Paton, J. (2006). Attitude to personality disorder among prison officers working in a dangerous and 
severe personality disorder unit. International Journal of Law and Psychiatry, 29, 333-342.

Brink, J.H., Doherty, D., \& Boer, A. (2001). Mental disorder in federal offenders: A Canadian prevalence study. International Journal of Law and Psychiatry, 2, 330356.

Callahan, L. (2004). Correctional officer attitudes towards inmates with mental disorders. International Journal of Forensic Mental Health, 3, 37-54.

Caperchione, C., Lauder, W., Kolt, S.G., Duncan, M.J., \& Mummery, W.K. (2008). Associations between social capital and health status in an Australian population. Psychology, Health \& Medicine, 13, 471-482.

Carr, W.A., Rotter, M., Steinbacher, M., Green, D., Dole, T., Garcia-Mansilla, A.,...Rosenfeld, B. (2006). Structured assessment of correctional adaptation (SACA): A measure of the impact of incarceration on the mentally ill in a therapeutic setting. International Journal of Offender Therapy and Comparative Criminology, 50, 570-581.

Clemmer, D. (1958/1940). The prison community. New York: Holt, Rinehardt and Winston.

Clements, C.B. (1979). A review of psychological and environmental effects. Law and Human Behavior, 3, 217-225.

Coleman, J.S. (1988). Social capital in the creation of human capital. The American Journal of Sociology, 94, S95-S120.

Colleta, N.J., \& Cullen, M.L. (2000). Violent conflict and the transformation of social capital. Washington, D.C.: World Bank. 
Cooley, D. (1992). Prison victimization and the informal rules of social control. Forum on Corrections Research, 4. Retrieved online June 25, 2011 from http://www.cscscc.gc.ca/text/pblct/forum/e043/e043ind-eng.shtml.

Correctional Service of Canada (2007). News release: Correctional Service of Canada to implement total smoking ban at all federal correctional facilities. Retrieved online June 13, 2011 from http://www.csc-scc.gc.ca/text/media/ntlrls/2007/07-0627-eng.shtml\#il.

Correctional Service of Canada (2008). Report on plans and priorities - 2008-2009. Ottawa: Author. Retrieved online February 21, 2010 from http://www.tbssct.gc.ca/rpp/2008-2009/inst/pen/pen-eng.pdf

Correctional Service of Canada (2009a). Quick facts: Mental health strategy. Ottawa: Author. Retreived online December 31, 2009 from http://www.cscscc.gc.ca/text/pblct/qf/11-eng.shtml.

Correctional Service of Canada (2009b). The changing federal offender population: highlights 2009. Retrieved online June 16, 2011 from http://www.cscscc.gc.ca/text/rsrch/special_reports/sr2009/sr-2009-eng.shtml.

Correctional Service of Canada (2009c). Transformation agenda. Retrieved online June 16, 2011 from http://www.csc-scc.gc.ca/text/organi/trnsfrmtn-io-eng.shtml Correctional Service of Canada (2010). Report on plans and priorities - 2010-2011. Ottawa: Author. Retrieved online May 8, 2011 from http://www.tbssct.gc.ca/rpp/2010-2011/inst/pen/pen-eng.pdf. 
Correctional Service of Canada (2011). Report on plans and priorities - 2011-2012. Ottawa: Author. Retrieved online June 18, 2011 from http://www.tbssct.gc.ca/rpp/2011-2012/inst/pen/pen-eng.pdf.

Cox, V.C., Paulhus, P.B., \& McCain, G. (1984). Prison crowding research: The relevance for prison housing standards and a general approach regarding crowding phenomena. American Psychologist, 39, 1148-1160.

Cox, V.C., Paulhus, P.B., \& McCain, G. (1986). Not for attribution: Response to Bonta. American Psychologist, 41, 101-102.

Derogatis, L.R. (1993). BSI brief symptom inventory: Administration, scoring, and procedure manual (4th Ed.). Minneapolis, MN: National Computer Systems

De Silva, M.J., McKenzie, K., Harpham, T., \& Huttly, S.R.A. (2005). Social capital and mental illness: A systematic review. Journal of Epidemiology and Community Health, 59, 619-627.

Dilulio, J.J. (1987). Governing prisons. New York: The Free Press.

Dvoskin, J.A., \& Spiers, E.M. (2004). On the role of correctional officers in prison mental health. Psychiatric Quarterly, 75, 41-59.

Edwards, K.A. (2000). Stigmatizing the stigmatized: A note on the mentally ill prison inmate. International Journal of Offender Therapy and Comparative Criminology, 44, 480-489.

Elgar, F. J., Waschbusch, D.A., McGrath, P.J., Stewart, S.H., \& Curtis, L.J. (2003). Temporal relations in daily-reported maternal mood and disruptive child behavior. Journal of Abnormal Child Psychology, 32, 237-247. 
Fazel, S., \& Danesh, J. (2002). Serious mental disorder in 23000 prisoners: A systematic review of 62 surveys. The Lancet, 359, 545-550.

Franklin, T.W., Franklin, C.A., \& Pratt, T.C. (2006). Examining the empirical relationship between prison crowing and inmate misconduct: A meta-analysis of conflicting research results. Journal of Criminal Justice, 36, 401-412.

French, S.A., \& Gendreau, P. (2006). Reducing prison misconducts: What works! Criminal Justice and Behavior, 33, 185-218.

Gaes, G.G., \& McGuire, W.J. (1985). Prison violence: The contribution of crowding versus other determinants of prison assault rates. Journal of Research in Crime and Delinquency, 22, 41-65.

Gendreau, P., Goggin, C.E., \& Law, M. (1997). Predicting prison misconducts. Criminal Justice and Behavior 24, 414-431.

Gunn, J. (2000). Future directions for treatment in forensic psychiatry. British Journal of Psychiatry, 176, 332-338.

Haney, C. (2002). The psychological impact of incarceration: Implications for postprison adjustment. Working paper prepared for the "From Prison to Home" Conference (January 30-31, 2002). Retrieved online September 30, 2009 from http://aspe.hhs.gov/hsp/prison2home02/haney.pdf.

Harpham, T., Grant, E., \& Thomas, E. (2002). Measuring social capital within health surveys: key issues. Health Policy and Planning, 17, 106-111.

Hiday, V.A. (2006). Putting community risk in perspective: A look at correlations, causes and controls. International Journal of Law and Psychiatry, 29, 316-331. 
Hodgins, S., \& Janson, C. (2002). Criminality and violence among the mentally disordered. Cambridge: Cambridge University Press.

Irwin, J., \& Cressey, D.R. (1962). Thieves, convicts and the inmate culture. Social Problems, 10, 142-155.

Kawachi, I., Kennedy, B.P., Glass, R. (1999). Social capital and self-rated health: A contextual analysis. American Journal of Public Health, 89, 1187-1193.

Kawachi, I., Kennedy, B.P., Lochner, K., \& Prothrow-Stith, D. (1997). Social capital, income inequality, and mortality. American Journal of Public Health, 87, 14911498.

Kutner, M. H., Nachtsheim, C. J., Neter, J., \& Li, W. (2005). Applied linear statistical models (5th Ed.). Boston, MA: WCB/McGraw-Hill.

Lahm, K.F. (2008). Inmate on inmate assault: A multi-level examination of prison violence. Criminal Justice and Behavior, 35, 120-137.

Lavoie, J.A.A., Connolly, D.A., \& Roesch, R. (2006). Correctional officers' perceptions of inmates with mental illness: The role of training and burnout syndrome. International Journal of Forensic Mental Health, 5, 151-166.

Link, B.G., Andrews, H., \& Cullen, F.T. (1992). The violent and illegal behavior of mental patients reconsidered. American Sociological Review, 57, 275-292.

Link B.G., Stueve, A., \& Phelan, J. (1998). Psychotic symptoms and violent behaviors: probing the components of "threat/control-override" symptoms. Social Psychiatry and Psychiatric Epidemiology, 33, S55-S60.

Lochner, K., Kawachi, I., \& Kennedy, B.P. (1999). Social capital: A guide to its measurement. Health \& Place, 5, 259-270. 
McCorckle, R.C., Miethe, T.D.,\& Drass, K.A. (1995). The roots of prison violence: A test of the deprivation, management and "not-so-total" institution models. Crime and Delinquency, 41,317-331.

McKenzie, K., Whitley, R., \& Weich, S. (2002). Social capital and mental health. British Journal of Psychiatry, 181, 280-283.

Mills, J.F. \& Kroner, D.G. (2003). Depression, hopelessness and suicide screening form 03: User's guide. Kingston: Authors.

Monahan, J., Steadman, H.J., Silver, E., Appelbaum, P.S., Clark Robbins, P., Mulvey, E.P.,...Banks, S. (2001). Rethinking risk assessment: The MacArthur study of violence and mental disorder and violence. New York: Oxford University Press.

Motiuk, L., \& Blanchette, K. (1997). Case characteristics of segregated offenders in federal corrections. Ottawa: Correctional Service of Canada. Research Report $\mathrm{N}^{\mathrm{o}}$. R-57.

Motiuk, L.L., \& Porporino, F.J. (1991). The prevalence, nature and severity of mental health problems among federal male inmates in federal penitentiaries. Ottawa: Correctional Service of Canada. Research Report N ${ }^{\circ}$. R-24.

Motiuk, L.L., \& Porporino, F.J. (1994). The prison careers of offenders with mental disorders. Ottawa: Correctional Service of Canada. Research Report N ${ }^{0}$. R-33. Nurse, J., Woodcock, P., \& Ormsby, J. (2003). Influence of environmental factors on mental health within prisons: Focus group study. British Medical Journal, 327, 480-484. 
Office of the Correctional Investigator (2008). Annual report 2007-08. Ottawa: Author. Retrieved online December 1, 2009 from http://www.oci-bec.gc.ca/rpt/indexeng.aspx.

Paulhus, D.L. (1998). Manual for the Paulhus deception scales: BIDR version 7. Toronto: Multi-Health Systems.

Piepgras, J.P. (2006). The effects of adaptation to incarceration on subsequent psychiatric hospitalization: A study of perceptions and attitudes. Doctoral Thesis: Adelphi University. UMI number 3213337.

Porporino, F.J. (1986). Managing violent individuals in correctional settings. Journal of Interpersonal Violence, 1, 213-237.

Portes, A. (1998). Social capital: Its origins and applications in modern sociology. Annual Review of Sociology, 24, 1-28.

Priebe, S., \& McCabe, R. (2008). Therapeutic relationships in psychiatry: The basis of therapy or therapy in itself? International Review of Psychiatry, 20, 521-526.

Priebe, S., McCabe, R., Bullenkamp, J., Hansson, L., Lauber, C., Martinez-Leal, R.,...Wright, D. (2007). Structure patient - clinician communication and 1-year outcome in community mental healthcare. British Journal of Psychiatry, 191, 420-426.

Prochaska, J.O,, DiClemente, C.C., \& Norcross, J.C. (1992). In search of how people change: Applications to addictive behaviors. American Psychologist, 47, 1102 1114. 
Public Safety Canada (2009). Corrections and conditional release overview 2008-2009.

Ottawa: Author. Retrieved online February 25, 2010 from http://www.publicsafety.gc.ca.

Putnam, R.D. (2000). Bowling alone: The collapse and revival of American community. New York: Simon \& Schuster.

Rotter, M., McQuistion, H.L., Broner, H., \& Steinbacher, M. (2005). The impact of the "incarceration culture" on reentry for adults with mental illness: A training and group treatment model. Psychiatric Services, 56, 265-267.

Sampson, R., Gascon, S., Glen, I., Louie, C., \& Rosenfeldt, S. (2007). A roadmap to strengthening public safety: Report of the Correctional Service of Canada review panel. Ottawa: Minister of Public Works and Government Services Canada. Retrieved online November 13, 2009 from http://www.csc-scc.gc.ca.

Sampson, R.J., Raudenbush, S.W., \& Earls, F. (1997). Neighbourhoods and violent crime: A multi-level study of collective efficacy. Science, 277, 918-924.

Soliday, E., Moore, K.J., \& Lande, M.B. (2002). Daily reports and pooled time series analysis: Pediatric psychology applications. Journal of Pediatric Psychology, 27, $67-76$

Steadman, H., Mulvey, E., Monahan, J., Robbins, P., Appelbaum, P., Grisso, T.,...Silver, E. (1998). Violence by people discharged from acute psychiatric inpatient facilities and by others in the same neighborhoods. Archives of General Psychiatry, 55, 393-401.

Stewart, L.A., Harris, A., Archambault, K., Wilton, G., Cousineau, C., Varrette, S., \& Power, J. (2010). An initial report on the results of the pilot of the computerized 
mental health intake screening system (CoMHISS). Ottawa: Correctional Service of Canada.

Sykes, G. (1958). The society of captives: A study of a maximum security prison. Princeton: Princeton University Press.

Tabachnick, B.G., \& Fidell, L.S. (2007). Using multivariate statistics (5th Ed). Boston: Pearson.

Toch, H. (1992/1977). Living in prison : the ecology of survival. Lawrenceville, NJ: Princeton University Press.

Toch, H., \& Adams, K. (1986). Pathology and disruptiveness among prison inmates. Journal of Research in Crime and Delinquency, 23, 7-21.

Toch, H., \& Kupers, T.A (2007). Violence in prison revisited. Journal of Offender Rehabilitation. 45, 1-28.

Uphoff, N. (2000). Understanding social capital: Learning from the analysis and experience of participation. In P. Dasgupta \& I. Serageldin (eds.) Social capital: A multi-faceted perspective. Washington, D.C.: World Bank. 215-252.

World Health Organization (2006). Health in prisons project: Mental health. Retrieved online July 29, 2009 from http://www.euro.who.int/prisons/topics/20050423_5.

Zamble, E., \& Porporino, F.J. (1988). Coping, behavior and adaptation in prison inmates. New York: Springer-Verlag.

Zamble, E., \& Porporino, F.J. (1990). Coping, imprisonment, and rehabilitation: Some data and their implications. Criminal Justice and Behavior, 17, 53-70.

Zinger, I., \& Wichman, C. (1999). The psychological effects of 60 days in administrative segregation. Ottawa: Correctional Service of Canada. Research Report N ${ }^{\mathrm{o}} \mathrm{R}-85$. 